\title{
Joint Task Force Type 3 Myocardial Infarction
}

\author{
National Cancer Institute
}

\section{Source}

National Cancer Institute. Joint Task Force Type 3 Myocardial Infarction. NCI Thesaurus. Code C119222.

Sudden unexpected cardiac death, including cardiac arrest, often with symptoms suggestive of myocardial ischaemia, accompanied by presumably new ST elevation, or new LBBB, or evidence of fresh thrombus in a coronary artery by angiog raphy and/or at autopsy, but death occurring before blood samples could be obtained, or at a time before the appearance of cardiac biomarkers in the blood. (Universal definition of myocardial infarction, Kristian Thygesen, Joseph S. Alpert and Harvey D. White on behalf of the Joint ESC/ACCF/AHA/WHF T ask Force for the Redefinition of Myocardial Infarction, Eur Heart J (2007) 28 (20): 2525-2538.) 